future work-namely, the practice of medicine and particularly the care of patients. It might be thought that both these objectives are clearly in mind at every medical school, but the evidence of the B.M.S.A. suggests that they are not. Among some specific criticisms the report makes is its view that there is too much useless overlapping between departments, so that time is wasted on teaching the same subject " with only a slight difference of bias." In addition, while some subjects are taught in excessive detail others are believed to be neglected, and among these the B.M.S.A. notes particularly genetics, statistics, first aid, the care of old people, and psychology and psychiatry. This list would certainly command general agreement.

Though the failure rate of medical students of $8.8 \%$ over the whole course is considerably below the average for university undergraduates $(13.3 \%),{ }^{3}$ it is generally recognized that examinations are at present "unreliable and otherwise unsatisfactory," to use the words of the Royal Commission, and that body suggested that a system of frequent assessment should replace the present more distantly spaced and more formidable hurdles. Unfortunately the B.M.S.A. report does not give a clear idea of what students themselves would believe to be a satisfactory test of competence, for it condemns " too frequent assessments" of factual knowledge but advocates "continuous, progressive assessment." There is nevertheless some truth in its view that too many students feel the need to study the technique of passing, for example, surgery examinations rather than the techniques of surgery.

In recommending that " all students should be encouraged to undertake some research project at some stage in their course " the B.M.S.A. report is following a fashion that causes far too little concern. The educational value of investigating a problem on one's own, with some guidance, is undoubted and should surely be a part of the education offered by any teacher who takes his job seriously. What more does the report intend ? At present it is quite usual for able students with a bent for it to play a part in the research being undertaken by their teachers or to compete for a prize by carrying out some project on their own. But there are undoubted dangers, which have not always been avoided in some countries abroad, in the misuse of animals and even patients when research is made part of an educational syllabus that all students must take. A more pressing question at present in medical schools-and in universities as a whole-is whether there is not far too much research of a trivial nature carried out to win friends and influence people. While the capacities to teach well and to do worthwhile research are occasionally combined in one individual, many students would probably warmly commend this plea from the report: "We would like to see more teachers appointed because of teaching ability rather than past research."

\footnotetext{
- Simpson, M. A., and Matthews, T., Report on Medical Education, 1968, British Medical Students' Association, 1968. B.M.A. House, London.

= Enquiry into Student Progress, 1968, University Grants Committee, 1968. H.M.S.O.

Brit. med. \%., 1968, 3, 390

- Report of the Royal Commission on Medical Education, 1965-68, 1968. Cmnd. 3569. H.M.S.O.
}

\section{Future of Paediatricians}

The first 20 years of the National Health Service made it possible to increase the number of trained paediatricians in Great Britain and they have had considerable influence on the pattern and quality of child care, in which there have been, and still need to be, great advances. It was therefore timely that last week a symposium should have been held in London on the future role and training of paediatricians in this country. Six visiting professors of paediatrics from leading centres in Europe attended. Funds for the meeting were provided by the International Children's Centre of Paris, and the arrangements were made by the Association for the Study of Medical Education in conjunction with the recently formed Academic Board of the British Paediatric Association.

Outlining the history of British paediatrics in his opening address, Professor Douglas Hubble reminded his audience that 26 years ago Sir James Spence's memorandum for the Nuffield Provincial Hospitals Trust erected the signposts that had pointed to su many of the advances in child care of the past 20 years. Certainly his audience shared his hope that this symposium would now act as a springboard for the next series of advances. During the first day's discussions on the present pattern of paediatric care and the education for it many paediatricians stressed their almost intolerable workload and their anxiety about how this must affect the service they were able to give their child patients. The majority of children are still treated in hospital by doctors who have seldom had any specific training in paediatrics, and they are treated in their homes by doctors who have seldom had more than six months' postgraduate training and sometimes none at all. In the future pattern of child care in the community and in hospital, discussed on the second day, some speakers considered the paediatricians would need more knowledge of community medicine and could not be expected to work in the isolation that some of them must do at present. They would have to be based on hospital departments large enough to carry the necessary facilities and nursing staff, and these departments would need to contain not fewer than 60 beds.

Facilities for teaching paediatrics to undergraduates were deemed inadequate in some of the London hospitals and often less than desirable in provincial teaching centres. Postgraduate training was thought to need more careful devising, and the now familiar view was expressed that the M.R.C.P. examination had in the past been apt to distort the training. In summing up Professor Hubble assured the conference that an invitation to look further into the help that may be gained for child care from a meeting between the British Paediatric Association through its academic board and the Royal College of General Practitioners would be accepted. He felt that they could usefully invite the Society of Medical Officers of Health to take part at a later date. In his view the preventive aspects of paediatrics had been undervalued, and if colleagues in adult medicine supported their efforts to improve child care at this stage it might prove to be one of the best ways of reducing the incidence of many of the diseases affecting the. next generation of adults. 